\title{
Issues in Arabic Orthography and Morphology Analysis
}

\author{
Tim BUCKWALTER \\ Linguistic Data Consortium \\ University of Pennsylvania \\ Philadelphia, PA 19104 USA \\ timbuck2@1dc.upenn.edu
}

\begin{abstract}
This paper discusses several issues in Arabic orthography that were encountered in the process of performing morphology analysis and POS tagging of 542,543 Arabic words in three newswire corpora at the LDC during 2002-2004, by means of the Buckwalter Arabic Morphological Analyzer. The most important issues involved variation in the orthography of Modern Standard Arabic that called for specific changes to the Analyzer algorithm, and also a more rigorous definition of typographic errors. Some orthographic anomalies had a direct impact on word tokenization, which in turn affected the morphology analysis and assignment of POS tags.
\end{abstract}

\section{Introduction}

In 2002 the LDC began using output from the Buckwalter Arabic Morphological Analyzer (Buckwalter, 2002), in order to perform morphological annotation and POS tagging of Arabic newswire text. From 2002 to 2004 three corpora were analyzed and over half a million Arabic word tokens were annotated and tagged (see Table 1).

\begin{tabular}{|c|c|}
\hline Corpus & Arabic Word Tokens \\
\hline \hline AFP & 123,810 \\
\hline Ummah & 125,698 \\
\hline Annahar & 293,035 \\
\hline Total & 542,543 \\
\hline
\end{tabular}

Table 1: Arabic newswire corpora

1 The tagged AFP, Ummah, and Annahar corpora were published as "Arabic Treebank: Part 1 v 2.0" (Maamouri 2003), "Arabic Treebank: Part 2 v 2.0" (Maamouri 2004), and "Arabic Treebank: Part 3 v 1.0" (Maamouri 2004), respectively, and are available from the LDC website $<$ http://www.ldc.upenn.edu >
The author was responsible for developing and maintaining the Analyzer, which primarily involved filling in the gaps in the lexicon and modifying the POS tag set in order to meet the requirements of treebanking efforts that were performed subsequently at the LDC with the same annotated and POS-tagged newswire data.

\section{Lessons from the AFP corpus}

During the tagging of the AFP data, the first corpus in the series, the Buckwalter Analyzer was equipped to handle basic orthographic variation that often goes unnoticed because it is a common feature of written Arabic (Buckwalter, 1992). This orthographic variation involves the writing (or omission) of hamza above or below alif in steminitial position, and to a lesser extent, the writing (or omission) of madda on alif, also in stem-initial position. In both cases use of the bare alif without hamza or madda is quite common and goes by unnoticed by most readers. What took the LDC morphology annotation team by surprise was to find that in the AFP data the common omission of hamza in this environment had been extended to stem-medial and stem-final positions as well, as seen in the following words from that corpus: بدات تاييد متاخر تاسيس تستانف رات لتاكيد بشان.

This type of orthographic variation was not attested to the same extent in the two subsequent corpora, Ummah and Annahar, which leads us to conclude that some orthographic practices might be restricted to specific news agencies. It is important to note that most of the native Arabic speakers who annotated the AFP data using the output from the Analyzer did not regard these omissions of hamza on alif in stem-medial and stem-final positions as orthographic errors, and fully expected the Analyzer to provide a solution.

\section{Lessons from the Ummah corpus}

During the tagging of the Ummah data, a different set of orthographic issues arose. Although the Buckwalter Analyzer was equipped to handle so-called "Egyptian" spelling (where word-final $y a^{\prime}$ is spelled without the two dots, making it 
identical to alif maqsura), the Ummah corpus presented the LDC annotation team with just the opposite phenomenon: dozens of word-final alif maqsura's spelled with two dots. 27 Whereas some of the affected words were automatically rejected as typographical errors (e.g., القري الأعلي موسي متي أخري (أخي ), others where gladly analyzed at face value (e.g., لاي إلي علي Unfortunately, this led to numerous false positive analyses: for example علي was analyzed as 'ali and 'alayya, but not as 'ala. Initially, these words were tagged as typographical errors, but their pervasiveness led the LDC team to reconsider this position, upon which the author was asked to modify the Analyzer algorithm in order to accommodate this typographic anomaly. As a result, all words ending in $y a^{\prime}$ were now reinterpreted as ending in either ya' or alif maqsura, and both forms were analyzed, as seen in the following (abridged) output: ${ }^{3}$

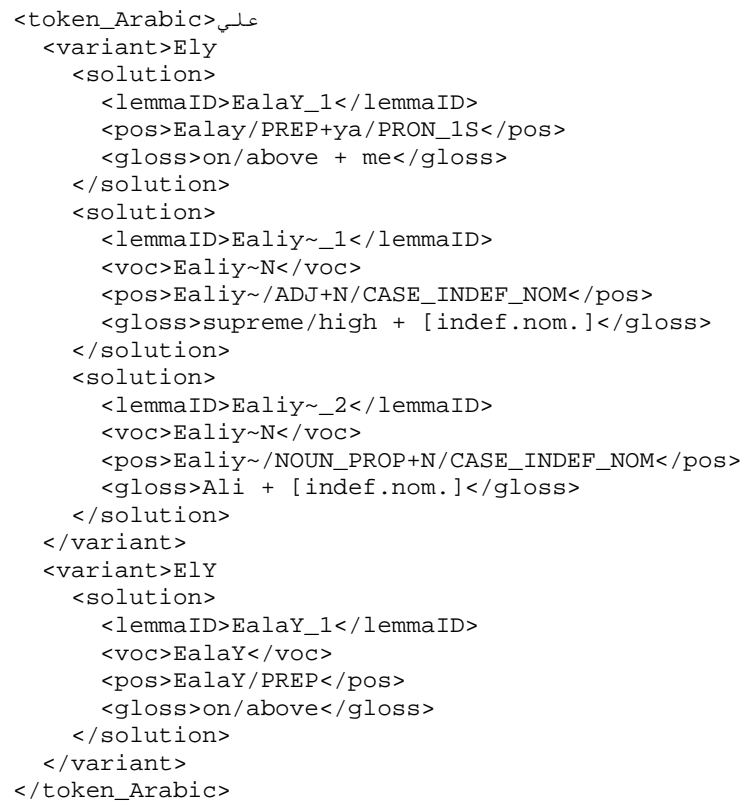

\section{Lessons from all three corpora}

The Annahar corpus presented no orthographic surprises, or at least nothing that the LDC annotation team had not seen before. The Annahar data did contain some additional orthographic

2 It is not entirely clear whether these "dotted" alif maqsura's were produced by human typists or by an encoding conversion process gone awry. It is possible that the original keyboarding was done on a platform where word-final ya' and alif maqsura are displayed via visually identical "un-dotted" glyphs, so it makes no difference which of the two kf $\mathrm{s}$ the typist presses on the keyboard: both produce the same visual display, but are stored electronically as two different characters.

3 A key to the transliteration scheme used by the Analyzer can be found at $<\mathrm{http}$ ://www.ldc.upenn.edu/ $\mathrm{myl} / \mathrm{morph} /$ buckwalter.html $>$ features that we now identify as being common to all three corpora, as well as corpora outside the set we have annotated at the LDC.

The first orthographic feature relates to the somewhat free interchange of stem-initial hamza above alif and hamza below alif. With some lexical items the orthographic variation simply reflects variation in pronunciation: for example, both 'isbaniya (with hamza under alif) and 'asbaniya (with hamza above alif) are well attested. But in cases involving other orthographic pairs, more interpretations are possible. Take, for instance, what we called the "qala "anna" problem. This problem was identified after numerous encounters with constructions in which qala was followed by 'anna rather than 'inna, and for no apparent linguistic reason. Initially this was treated as a typographical error, but again, its pervasiveness forced us to take a different approach.

One solution we consider was to modify the Analyzer algorithm so that instances of stem-initial hamza on alif would also be treated as possible instances of hamza under alif, very much in the spirit of the approach we used for dealing with the alif maqsura / $y a^{\prime}$ free variation cited earlier. However, there is compelling evidence that the orthography of hamza in stem-initial position is a fairly reliable indication of the perceived value of subsequent short vowel: $a$ or $u$ for hamza above alif, and $i$ for hamza below alif. In other words, there is no free variation. The decision was taken to regard "qala "anna" constructions as grammatically acceptable in MSA. ${ }^{4}$

\section{Concatenation in Arabic orthography}

The second, and more serious, orthographic anomaly we encountered in all three corpora is what we call the problem of Arabic "run-on" words, or free concatenation of words when the word immediately preceding ends with a nonconnector letter, such as alif, dal, dhal, ra, za, waw, ta marbuta, etc.

The most frequent "run-on" words in Arabic are combinations of the high-frequency function words $l a$ and $m a$ (which end in alif) with following perfect or imperfect verbs, such as la-yazal, mayuram, and ma-zala (مازال مايرام لايزال). The la of "absolute negation" concatenates freely with nouns, as in la-budda, la-shakka (لاشك لابد). It can be argued that these are lexicalized collocations, but their spelling with intervening space (لايزال)

\footnotetext{
4 Badawi, Carter and Gully regard "qala 'anna" constructions as grammatical but restricted to contexts "where the exact words of the speaker are not used or reported" (Badawi, Carter and Gully 2004, p. 713). This assertion could be investigated in the LDC corpora.
} 
is just as frequent as their spelling in concatenated form.

Proper name phrases, especially those involving the word 'abd (عبدالرحمن عبداله) are also written either separately or in concatenated form. Part of the data annotation process at the LDC involves assigning case endings to tokenized words, but there is currently no mechanism in the Analyzer to assign two case endings (or several pairs of POS tags) to what is being processed as a single word token. As a result of this, the phrase 'abd allah is assigned a single POS tag and case ending when it is written in concatenated form, but two POS tags and two case endings when written with intervening space.

The problem of assigning more than one case ending and POS tag to concatenations is more obvious in fully lexicalized concatenations such as khamsumi'atin, sittumi'atin, sab'umi'atin, etc (سبعمائة - ستمائة - خمسمائة). When these numbers are written with intervening space (ست مائة - خمس مائة سبع مائة , two case endings and two POS tags are assigned by the Analyzer. But when they are written in concatenated form only one case ending and POS tag is assigned, and the "infixed" case ending of the first token is left undefined: khamsmi' $a t^{i n}$, sittmi' $^{\text {in }}{ }^{\text {, }}$, sab'mi' $^{\text {in }}$, etc.

So far we have discussed relatively controlled concatenation, involving mostly high-frequency function words and lexicalized phrases. But concatenation extends beyond that to random combinations of words - the only requirement being that the word immediately preceding end with a non-connector letter. These concatenations are fairly frequent, as attested by their Google scores (see Table 2).

It is important to note that these concatenations are not immediately obvious to readers due to the characteristics of proportionally spaced Arabic fonts. Most of the native readers of Arabic at the LDC did not consider concatenations such as these to be typographical errors. Their logic was best expressed in the statement: "I can read the text just fine. Why can't the Morphological Analyzer?"

\footnotetext{
5 We regard these as "fully lexicalized" concatenations because the first of the two constituent tokens ends in a connector letter. In other word, their concatenation is deliberate and not an accident of orthography.
}

\begin{tabular}{|c|c|}
\hline Concatenation & $\begin{array}{c}\text { Google } \\
\text { Frequency }\end{array}$ \\
\hline مدير عام & 846 \\
\hline وزير الخارجية & 719 \\
\hline ملياردو لار & 162 \\
\hline الدكتورمحمد & 158 \\
\hline عضومجلس & 138 \\
\hline وقدنم & 130 \\
\hline و انشار الى & 99 \\
\hline كماتم & 77 \\
\hline عددكبير & 54 \\
\hline
\end{tabular}

Table 2: Arabic Concatenations and their Google Frequencies (sample taken March 25,2004)

\section{Conclusion}

There are several levels of orthographic variation in Arabic, and each level calls for a specific response to resolve the orthographic anomaly. It is important that the output analysis record which method was used to resolve the anomaly. The methods used for resolving orthographic anomaly range from exact matching of the surface orthography to various strategies of orthography manipulation. Each manipulation strategy carries with it certain assumptions about the text, and these assumptions should be part of the output analysis. For example, an analysis of علي obtained by exact matching in a text known to contain suspicious word-final $y a$ 's (that may be alif maqsura's) does not have the same value as an analysis of the same word, using the same exact matching, but in a text where word-final $y a$ 's and alif maqsura's display normal character distribution frequencies.

The problem of run-on words in Arabic calls for a reassessment of current tokenization strategies, including the definition of "word token" itself. It should be assumed that each input string represents one or more potential word tokens, each of which needs to be submitted individually for morphology analysis. For example, the input string فقنت can be segmented as a single word token, yielding two morphological analyses (faqad-tum and fa-qudtum) or it can be segmented as two word tokens (fqd tm), yielding several possible analysis pairs (faqada / fuqida / faqd / fa-qad + tamma).

6 By "tokenization" we mean the identification of orthographically valid character string units that can be submitted to the Analyzer for analysis. The Analyzer itself performs a different kind of "tokenization" by identifying prefixes and suffixes that are bound morphemes but which may be treated as "word tokens" in syntactic analysis. 
Syntactic analysis would be needed for determining which morphology analysis is most likely the correct one for each tokenization ( $f q d t m$ and $f q d \mathrm{tm}$ ).

\section{Acknowledgements}

Our thanks go to the Arabic annotation team at the LDC, especially the team of native speaker informants that provided the author with daily feedback on the performance of the Morphological Analyzer, especially in areas which led to a reassessment and better understanding of orthographic variation, as well as tokenization and functional definitions of typographical errors.

\section{References}

Elsaid Badawi, M.G. Carter, and Adrian Wallace. 2004. Modern Written Arabic: A Comprehensive Grammar. Routledge, London.

Tim Buckwalter. 1992. "Orthographic Variation in Arabic and its Relevance to Automatic SpellChecking," in Proceedings of the Third International Conference on Multilingual Computing (Arabic and Roman Script), University of Durham, U.K., December 10-12, 1992.

Tim Buckwalter. 2002. Buckwalter Arabic Morphological Analyzer Version 1.0. Linguistic Data Consortium, catalog number LDC2002L49 and ISBN 1-58563-257-0. < http://www.ldc. upenn.edu/Catalog/CatalogEntry.jsp?catalogId= LDC2002L49>

Mohamed Maamouri, et al. 2003. Arabic Treebank: Part 1 v 2.0. Linguistic Data Consortium, catalog number LDC2003T06 and ISBN: 1-58563-261-9. < http://www.ldc.upenn.edu/Catalog/CatalogEntry.jsp?catalogId= LDC2003T06 >

Mohamed Maamouri, et al. 2004. Arabic Treebank: Part 2 v 2.0. Linguistic Data Consortium, catalog number LDC2004T02 and ISBN: 1-58563-282-1. < http://www.ldc.upenn.edu/Catalog/CatalogEntry.jsp?catalogId= LDC2004T02 >

Mohamed Maamouri, et al. 2004. Arabic Treebank: Part 3 v 1.0. Linguistic Data Consortium, catalog number LDC2004T11 and ISBN: 1-58563-298-8. < http://www.ldc.upenn.edu/Catalog/CatalogEntry.jsp?catalogId= LDC2004T11 > 